\title{
National outbreak of Salmonella Typhimurium (Dutch) phage-type 132 in the Netherlands, October to December 2009
}

J Whelan (jane.whelan@rivm.nl) 1,2 , Hoel $^{1}$, I Friesema ${ }^{1}$, A Hofhuis ${ }^{1}$, C M de Jager ${ }^{1}$, M Heck $^{1}$, A Heuvelink ${ }^{3}$, W van Pelt ${ }^{1}$

1. Centre for Infectious Disease Control, National Institute for Public Health and the Environment (Rijksinstituut voor Volksgezondheid en Milieu, RIVM), Bilthoven, the Netherlands

2. European Programme for Intervention Epidemiology Training (EPIET), European Centre for Disease Prevention and Control (ECDC), Stockholm, Sweden

3. Food and Consumer Product Safety Authority (Voedsel en Waren Autoriteit, VWA), Zutphen, the Netherlands

Between October and December 2009, 23 cases of Salmonella Typhimurium (Dutch) phage type 132, each with an identical multiple-locus variable-number tandem-repeat analysis (MLVA) profile (02-20-08-11212), were reported from across the Netherlands. A case-control study was conducted using the foodconsumption component of responses to a routine population-based survey as a control group. The mean age of cases was 17 years (median: 10 years, range: 1-68). Sixteen cases were aged 16 years or under. Raw or undercooked beef products were identified as the probable source of infection. Consumers, in particular parents of young children, should be reminded of the potential danger of eating raw or undercooked meat.

\section{Introduction}

Salmonella enterica subsp. enterica serotype Typhimurium (S. Typhimurium) has historically been an important cause of human gastrointestinal disease in the Netherlands [1,2]. The Dutch laboratory surveillance network for gastroenteric pathogens was established in 1987, in which 15 of the 16 regional public health laboratories participate. It serves general practices and district and university hospitals and has been estimated to cover approximately $62 \%$ of the Dutch population [3]. Salmonella isolates from human, animal, food and environmental samples are sent to the National Salmonella Centre in the Dutch National Institute of Public Health and the Environment (Rijksinstituut voor Volksgezondheid en Milieu, RIVM), where they are sero- and phage typed and are reported on a weekly basis.

On 9 November 2009, the centre reported six clinical isolates (confirmed between 4 and 9 November 2009) of an unusual phage type, $S$. Typhimurium (Dutch) phage type 132 (ft132) to the Epidemiology and Surveillance Unit at RIVM. This phage type had been first identified in chickens in the Netherlands in the early 1980s [2]. Until November 2009, there had been no further reports of this strain in either animals or humans in the country. On 16 November 2009, a further five clinical isolates of the same phage type were reported, prompting immediate investigation. Cases were traced through routine surveillance and were invited to respond to an openended, hypothesis-generating questionnaire. When asked what they believed the source of their infection to be, four cases implicated 'ready-to-eat' minced or ground raw beef in the form of steak tartare (also known as filet américain); three cases implicated rare or undercooked beef as the source. These findings led to our hypothesis that consumption of raw or rare contaminated beef products was associated with infection with S. Typhimurium ft132. RIVM reported the outbreak to the Food and Consumer Product Safety Authority (Voedsel en Waren Autoriteit, VWA) on 1 December 2009.The aim of the study presented here was to test the association between consumption of raw or undercooked meat and infection with S. Typhimurium ft132 and to identify other potential risk factors.

\section{Methods}

To test the hypothesis that consumption of raw or rare contaminated beef products was associated with infection with $S$. Typhimurium ft132, a retrospective casecontrol study was conducted.

\section{Case definition}

As S. Typhimurium ft132 had not been reported in humans before, a case was defined as any individual who had laboratory-confirmed S. Typhimurium ft132 infection in the Netherlands - a time period was not specified.

\section{Selection of controls: the} quarterly control-survey

Controls were drawn from a random selection of people from the Dutch general population. In the Netherlands, all individuals are registered with a unique number in the municipality in which they reside. Since 2008, 


\section{FIGURE 1}

Geographical distribution of Salmonella Typhimurium ft132 respondent cases $(n=14)$ and controls $\left(n=121^{a}\right)$ by postal code, the Netherlands, October - December 2009

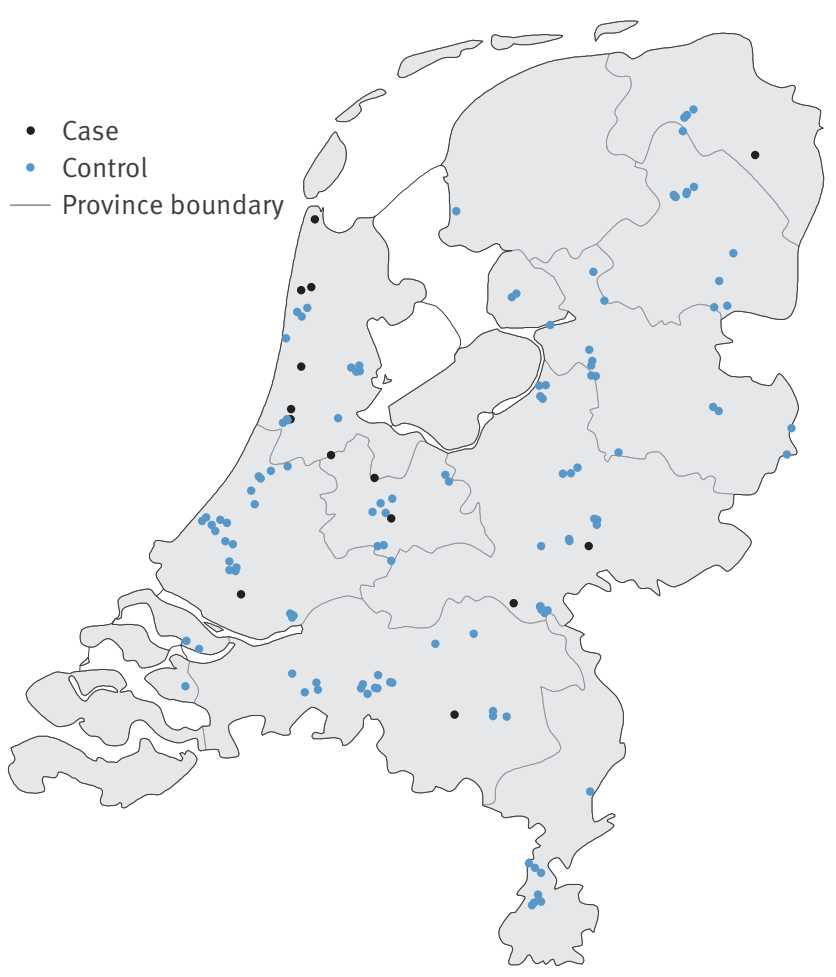

a Postcodes were not provided by three controls.

Source: National Institute for Public Health and the Environment (Rijksinstituut voor Volksgezondheid en Milieu, RIVM).

\section{FIGURE 2}

Cases of Salmonella Typhimurium $\mathrm{ft} 132$ by (A) date of symptom onset of questionnaire respondents $(n=14)$ and by (B) date of laboratory-confirmed diagnosis for all cases $(n=23)$, the Netherlands, October 2009 - December 2009

A

Date of onset of symptoms

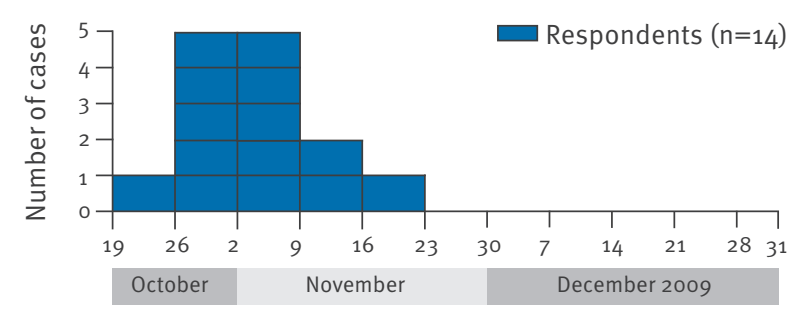

B

Date of laboratory-confirmed diagnosis

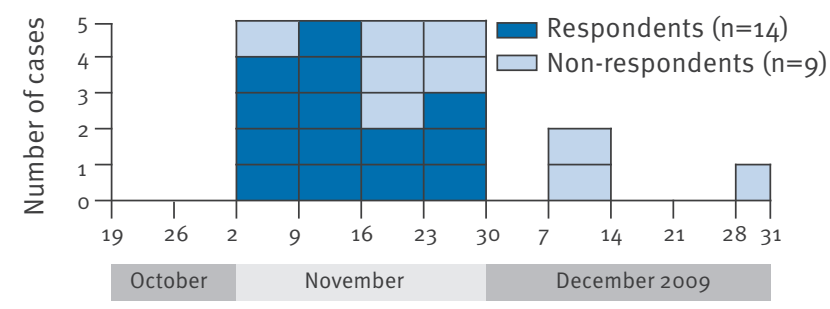

RIVM has received annually a computer-generated random selection of approximately 500 people from each of the 38 municipalities in the country (a total of approximately 20,000 individuals per year). From this pool, each quarter RIVM selects (using the random number generation function of Microsoft Excel) a simple random subsample of 300 to 500 people to take part in a survey of risk factors for food-borne and other infections. A questionnaire is sent by post to the selected people; if the sampled individual is under 16 years, a parent or guardian is asked to complete the questionnaire on the child's behalf. The survey (known as a control-survey) was designed for use as a control group for enhanced surveillance and outbreak investigation of food-borne and some respiratory diseases [4]. The questionnaire includes 36 questions related to demography, medical history, and gastrointestinal illness and other symptoms and behaviours in the previous 30 days: history of travel, eating in restaurants, visiting farms and other contact with domestic and farm animals. Questions also relate to the nature and type of food consumed in the week before receipt of the questionnaire (meat, fish, dairy products, fruit and vegetables). The response rate is typically over $30 \%$.

As a faecal sample was taken from the first case of $S$. Typhimurium ft132 infection on 27 October 2009, and as the incubation period is between six and 72 hours, controls were defined as those who responded to the questionnaire (as part of the control-survey) between 20 October and 30 December 2009.

\section{Interview of cases}

Cases were invited to complete a questionnaire, by telephone or by post. Compared with the questionnaire used for controls, the questionnaire for cases was more detailed with regard to the type and brand of each food consumed and the name and address of each shopping location visited. However, questions used in this study to compare cases and controls were the same.

\section{Statistical analysis}

Data were analysed using STATA 10.1. Odds ratios adjusted for age group and sex with $95 \%$ confidence intervals were generated using multiple logistic regression. The mean time between date of onset of illness and laboratory-confirmed diagnosis was also calculated.

\section{Laboratory diagnosis}

Faecal samples were examined by medical microbiologists and isolates were sero- and phage typed at the National Salmonella Centre. Multiple-locus variablenumber tandem-repeat analysis (MLVA) followed the method described by Lindsted et al. [5] using the new nomenclature described by Larsson et al. [6]. The Food and Consumer Product Safety Authority conducted a trace-back investigation based on reported place of purchase and/or consumption of the suspected foods. When possible, leftovers of the suspected foods were 
collected at cases' domicile and tested for presence of S. Typhimurium $\mathrm{ft} 132$.

\section{Results}

\section{Descriptive analysis of cases}

A total of 23 cases of $\mathrm{S}$.Typhimurium ft132 infection with an identical MLVA profile (02-20-08-11-212) [6] were confirmed by laboratory diagnosis between 4 November and 30 December 2009. Of these, 10 were male. The mean age of the cases was 17 years (median: 10 years; range: $1-68), 16$ cases were children aged 16 years or under, five were aged $17-49$ years and two were 50 years or older.

A total of 14 cases responded to the questionnaire. These cases were widely dispersed, coming from 13 different municipal health service districts across the Netherlands (Figure 1).

The respondent cases became ill between 21 October and 16 November 2009 (Figure 2A). The mean time between onset of illness and laboratory-confirmed diagnosis was 10.6 days (range: 5-16) (Figure 2B). Symptoms of these 14 cases included diarrhoea $(n=13)$, abdominal pain $(n=12)$, fever $(n=10)$, vomiting $(n=9)$, nausea $(n=8)$ and blood in stools $(n=7)$.

The mean duration of illness of respondents $(n=14)$ was 13.9 days (range: 5-15). Eight patients were hospitalised: seven had been discharged at the time of interview and one case with a serious underlying medical condition died. Four cases reported that household members were also symptomatic $(n=5)$. In the week before the onset of symptoms, eight respondents had had contact with domestic animals, two had visited a foreign country and one had been to a large public event.

\section{Case-control study}

In October to December 2009, 342 people were invited to complete the questionnaire for the national quarterly control-survey. Of those, $38 \%(n=130)$ responded, of whom 124 met the control definition. Respondent cases and controls were similar in terms of sex: $50 \%$ $(n=7)$ of cases and $38 \%(n=47)$ of controls were male, $p=0.379$. Controls were older than cases; $90 \%(n=112)$ of controls and $7 \%(n=1)$ of cases were aged over 16 years, but there was no difference in the proportion of children (40\%) and adults (47\%) who reported consuming raw or undercooked meat. Therefore, age was not considered to be a confounding factor in the relationship between the consumption of raw or undercooked meat and being a case.

When differences in exposure to the most commonly reported foods between cases and controls were examined, nine cases (64\%) and 54 controls (44\%) reported consuming beef that was eaten raw or rare. This included steak tartare, ossenworst (a raw beef sausage prepared with herbs) and rare fillet of beef. The association between each type of food and being a case was tested with adjustment for age group and sex (Table). The odds ratio (OR) of being a case after eating either 'ready-to-eat' raw beef (steak tartare or ossenworst) or fillet of beef eaten rare was 15.38 (95\% confidence interval $(\mathrm{Cl}): 1.8$ to $131.2, \mathrm{p}=0.012)$. When the analysis was repeated using the ready-to-eat raw beef products only, the odds ratio was 28.8 (95\% Cl: 1.7 to $490.1, p=0.02)$. Of respondents, $28 \%$ of cases $(n=4)$ and $5 \%$ of controls $(n=6)$ reported shopping at a particular supermarket chain (OR: $7.87,95 \% \mathrm{Cl}: 1.36$ to 39.11, $p=0.001$ ), but it was not possible to say where particular products had been purchased and no common restaurant or other public eatery was reported.

\section{Trace-back investigation}

After RIVM reported the outbreak on 1 December 2009 to the Food and Consumer Product Safety Authority, the latter conducted a trace-back investigation, testing suspected beef product samples (minced beef) submitted by two cases. No evidence of $S$. Typhimurium was found in either sample. Given the short shelf life

\section{TABLE}

Most commonly consumed foods reported by cases $(n=14)$ and controls $(n=124)$, the Netherlands, October - December 2009

\begin{tabular}{|c|c|c|c|c|c|c|c|}
\hline \multirow{2}{*}{ Type of food consumed } & \multicolumn{2}{|c|}{ Cases $(n=14)$} & \multicolumn{2}{|c|}{ Controls $(n=124)$} & \multirow{2}{*}{ Adjusted $O R^{a}$} & \multirow{2}{*}{$95 \% \mathrm{Cl}$} & \multirow{2}{*}{ P value } \\
\hline & $\mathrm{n}$ & $\%$ & $\mathrm{n}$ & $\%$ & & & \\
\hline Beef eaten raw or rare ${ }^{b}$ & 9 & 64 & 54 & 44 & $15 \cdot 38$ & $1.80-131.16$ & 0.012 \\
\hline Fish or shellfish & 7 & 50 & 67 & 54 & 0.74 & $0.17-3.37$ & 0.704 \\
\hline Sausage meat & 6 & 43 & 59 & 48 & 0.64 & $0.13-3.03$ & 0.575 \\
\hline Minced pork & 5 & 36 & 60 & 48 & 0.38 & $0.07-1.99$ & 0.252 \\
\hline Snack sausages & 3 & 21 & 19 & 15 & 1.55 & $0.22-10.68$ & 0.658 \\
\hline Mixed pork and beef mince & 3 & 21 & 23 & 19 & 0.16 & $0.02-1.26$ & 0.082 \\
\hline Salad & 3 & 21 & 74 & 60 & 0.19 & $0.03-1.06$ & 0.059 \\
\hline Ham & 3 & 21 & 49 & 40 & 0.61 & $0.10-3.64$ & 0.594 \\
\hline
\end{tabular}

$\mathrm{Cl}$ : confidence interval; OR: odds ratio.

a Adjusted for sex and three age groups ( $<5$ years, 5-16 years and $>16$ years).

b Includes steak tartare, ossenworst and rare fillet of beef. 
of ready-to-eat raw meat products, samples from the supermarket chain were not available for analysis by the time of the investigation. No common meat supplier was identified among all the different supermarket chains where cases reported to have purchased meat products in the week before the onset of symptoms.

\section{European investigation}

On 23 November 2009, an appeal was made (via the European Centre for Disease Prevention and Control) to European Union Member States for information regarding recent identification of $S$. Typhimurium with the same MLVA pattern (02-20-08-11-212). No country in Europe reported cases infected with $S$. Typhimurium with the same MLVA pattern, either before or at the time of this outbreak.

\section{Discussion}

An unusual and identifying feature of this outbreak was the unique Salmonella strain involved, and the fact that the MLVA patterns of all the isolates were identical. Although the outbreak was small and the trace-back investigation inconclusive, the epidemiological investigation pointed to ready-to-eat raw or undercooked beef products as the probable vehicle of infection.

Our investigation was limited by a number of factors: small sample size, lack of available material for sampling given the short shelf life of ready-to-eat raw meat products, and a 10-day interval between onset of illness and laboratory-confirmed diagnosis, resulting in potential recall bias among the cases.

From a methodological perspective, use of a routinely surveyed population as a control group, for which known risk factors for food-borne disease have been assessed, proved effective and timely. After a foodborne outbreak, controls are often questioned about their food intake weeks to months earlier. In this study, controls returned questionnaires throughout the outbreak period and as they reported their food consumption in the week before receiving the questionnaire, their responses were potentially more reliable and less susceptible to recall bias than those of controls used in other similar retrospective studies. The surge in manpower required to conduct a case-control study after an outbreak (finding and interviewing controls and creating a database) is also reduced. For these reasons, we recommend this approach. The control-survey should be reviewed as necessary to take account of newly recognised or seasonal links to food and behaviours that might place individuals at risk of food-borne infection.

In this outbreak, $70 \%$ of those affected were children, Age-specific rates of salmonella infection and rates of hospitalisation are typically highest among children (although Salmonella spp. can cause disease in persons of any age) [7]. In the control group, only $10 \%$ of respondents were children. Given that control responses had already been received at the time of the investigation, matching by age was not possible a priori. Age matching would have lead to a better ratio of cases to controls across age strata in adults thus allowing a better examination of the effect of age. Age was not considered a confounding factor in this study, however, as similar proportions of adults and children consumed raw or undercooked meat. To achieve a better representation of groups known to be vulnerable to Salmonella and other infections, oversampling of young children and elderly people would be of benefit when conducting the quarterly control-survey.

Studies have shown considerable stability of individual food habits over time $[8,9]$. The optimal frequency for a routine control-survey that is appropriate for use as control group for food-borne infectious disease outbreaks will depend in part on seasonal variation of food intake and in part on the frequency and nature of foodborne outbreaks in the country in question. Taking into account resource requirements, a control-survey every three months is considered optimal in the Netherlands.

This is the fourth food-borne outbreak in recent years linked to consumption of steak tartare and other raw beef products in the Netherlands [10-12]. In 2006 to 2008, despite intensive monitoring and control programmes, Salmonella was still found in-store in raw meats (such as steak tartare and ossenworst) intended for direct consumption [13]. Consumer awareness of the potential hazard of eating raw meat is central to good control. In particular, parents should be reminded that children are vulnerable to Salmonella infection and should not eat products containing raw or undercooked meat.

\section{Acknowledgements}

We would like to thank patients and laboratory personnel for their assistance in this study. We would also like to thank Cindy Deuning and Maarten Mulder in RIVM for the mapping of cases and controls (Figure 1) and EPIET, in particular EPIET co-ordinator Biagio Pedalino.

\section{References}

1. Doorduyn $Y$, Hofhuis $A$, de Jager $C$, van der Zwaluw W, Notermans D, van Pelt W. Salmonella Typhimurium outbreaks in the Netherlands in 2008. Euro Surveill. 2008;13(44). pii: 19026. Available from: http://www.eurosurveillance.org/ ViewArticle.aspx?Articleld $=19026$

2. van Duijkeren E, Wannet WJ, Houwers DJ, van Pelt W. Serotype and phage type distribution of salmonella strains isolated from humans, cattle, pigs, and chickens in the Netherlands from 1984 to 2001. J Clin Microbiol. 2002;40(11):3980-5.

3. van Pelt W, de Wit MA, Wannet WJ, Ligtvoet EJ, Widdowson MA, van Duynhoven YT. Laboratory surveillance of bacterial gastroenteric pathogens in The Netherlands, 1991-2001. Epidemiol Infect. 2003;130(3):431-41.

4. Friesema I, Doorduyn Y, de Jager C, van der Zwaluw W, Notermans D, van Heerwaarden C, et al. [Enhanced surveillance of Listeria monocytogenes in the Netherlands, 2008]. Infectieziekten Bulletin. 2010;2:57-62. Dutch.

5. Lindstedt BA, Torpdahl M, Nielsen EM, Vardund T, Aas L, Kapperud G. Harmonization of the multiple-locus variablenumber tandem repeat analysis method between Denmark and Norway for typing Salmonella Typhimurium isolates and closer examination of the VNTR loci. J Appl Microbiol. 2007;102(3):728-35. 
6. Larsson JT, Torpdahl M, Petersen RF, Sorensen G, Lindstedt BA, Nielsen EM. Development of a new nomenclature for Salmonella typhimurium multilocus variable number of tandem repeats analysis (MLVA). Euro Surveill. 2009;14(15). pii: 19174. Available from: http://www.eurosurveillance.org/ViewArticle. aspx?Articleld $=19174$

7. Heymann DL, editor. Control of communicable diseases manual. 19th ed. Washington: American Public Health Association; 2008.

8. Borland SE, Robinson SM, Crozier SR, Inskip HM, SWS Study Group. Stability of dietary patterns in young women over a 2-year period. Eur J Clin Nutr. 2008;62(1):119-26.

9. Goldbohm RA, van 't Veer P, van den Brandt PA, van 't Hof MA, Brants HA, Sturmans F, et al. Reproducibility of a food frequency questionnaire and stability of dietary habits determined from five annually repeated measurements. Eur J Clin Nutr. 1995;49(6):420-9.

10. Greenland K, de Jager C, Heuvelink A, van der Zwaluw K, Heck M, Notermans D, et al. Nationwide outbreak of STEC 0157 infection in the Netherlands, December 2008-January 2009: continuous risk of consuming raw beef products. Eurosurveillance 2009;14(8). pii : 19129. Available from: http:// www.eurosurveillance.org/ViewArticle.aspx?Articleld=19129

11. Doorduyn $Y$, de Jager C, van der Zwaluw W, Friesema I, Heuvelink A, de Boer E, et al. Shiga toxin-producing Escherichia coli (STEC) 0157 outbreak, The Netherlands, September-October 2005. . Eurosurveillance 2006;11(7). pii : 636. Available from: http://www.eurosurveillance.org/ ViewArticle.aspx?Articleld $=636$

12. Kivi M, Hofhuis A, Notermans DW, Wannet WJ, Heck ME, Van De Giessen AW, et al. A beef-associated outbreak of Salmonella Typhimurium DT104 in The Netherlands with implications for national and international policy. Epidemiol Infect. 2007;135(6):890-9.

13. van Pelt W, Braks M, Schimmer B, Stenvers O, Langelaar M [State of zoonoses 2007-2008]. Bilthoven: National Institute for Public Health and the Environment (Rijksinstituut voor Volksgezondheid en Milieu (RIVM); 2009. Report No.: 330131001/2009. Dutch. 